\title{
Herança da resistência em feijoeiro à murcha causada por Curtobacterium flaccumfaciens pv. flaccumfaciens
}

\author{
Giseli Valentini(1), Joana Neres da Cruz Baldissera(1), Pedro Patric Pinho Morais(1), Diego Stähelin ${ }^{(1)}$, \\ Joice Crescêncio Heidemann( ${ }^{(1)}$, Felipe Stenger ${ }^{(1)}$, Haroldo Tavares Elias ${ }^{(2)}$, Altamir Frederico Guidolin ${ }^{(1)}$ \\ e Jefferson Luís Meirelles Coimbra(1)
}

\begin{abstract}
(1)Universidade do Estado de Santa Catarina, Centro de Ciências Agroveterinárias, Avenida Luis de Camões, no 2.090, CEP 88520-000 Lages, SC. E-mail: giselivalentini@hotmail.com, jondcb@gmail.com, patric_pinho@hotmail.com, diegostahelin@gmail.com, clickjoice@hotmail.com, felipestenger13@hotmail.com, a2afg@cav.udesc.br, a2jlm@cav.udesc.br (2)Empresa de Pesquisa e Extensão Rural de Santa Catarina, Rodovia Admar Gonzaga, no 1.347, Itacorubi, Caixa Postal 502, CEP 88034-901 Florianópolis, SC. E-mail: haroldo1963@gmail.com
\end{abstract}

Resumo - $\mathrm{O}$ objetivo deste trabalho foi determinar a herança da resistência à murcha de Curtobacterium em feijoeiro. Foram realizados dois experimentos: no primeiro, cinco genótipos de feijoeiro, com diferentes reações de resistência à murcha de Curtobacterium, foram cruzados em arranjo dialélico; e no segundo, dois cruzamentos entre genótipos resistentes e suscetíveis - IAC Carioca Aruã x SCS Guará e IAC Carioca Pyatã x Pérola - foram realizados para dar origem às gerações $\mathrm{P}_{1}, \mathrm{P}_{2}, \mathrm{~F}_{1}, \mathrm{~F}_{2}, \mathrm{RC}_{1}$ e $\mathrm{RC}_{2}$. Em ambos os experimentos, a resistência do feijoeiro à murcha bacteriana foi avaliada por meio da inoculação do isolado Cff 2634. A análise dialélica mostrou que, embora efeitos aditivos e não aditivos estejam envolvidos, houve maior participação de genes com efeito aditivo no controle genético da resistência à murcha bacteriana, o que mostra a possibilidade de se obter sucesso com a seleção. A herança da resistência à murcha de Curtobacterium é complexa, com mais de três genes envolvidos, e herdabilidade no sentido restrito de $29 \%$, para o cruzamento 'IAC Carioca Aruã' x 'SCS Guará', e de 44\%, para o cruzamento 'IAC Carioca Pyatã' x 'Pérola'.

Termos para indexação: Curtobacterium flaccumfaciens pv. flaccumfaciens, Phaseolus vulgaris, controle genético, herdabilidade, resistência genética.

\section{Inheritance of common bean resistance to wilt caused by Curtobacterium flaccumfaciens pv. flaccumfaciens}

\begin{abstract}
The objective of this work was to determine the inheritance of resistance in common bean to wilt of Curtobacterium. Two experiments were carried out: in the first one, five common bean genotypes with different resistance reactions to wilt of Curtobacterium were crossed in diallel arrangement; and in the second one two crosses between resistant and susceptible genotypes - IAC Carioca Aruã x SCS Guará and IAC Carioca Pyatã x Pérola - were carried out in order to give rise to the generations $\mathrm{P}_{1}, \mathrm{P}_{2}, \mathrm{~F}_{1}, \mathrm{~F}_{2}, \mathrm{RC}_{1}$ and $\mathrm{RC}_{2}$. In both experiments, the common bean resistance to bacterial wilt was evaluated through the inoculation of the $\mathrm{Cff} 2634$ isolate. The diallel analysis showed that although non-additive and additive effects are involved, there was a greater participation of the genes with additive effect on the genetic control of the inheritance of resistance to bacterial wilt, which shows the possibility of improvement through selection. The inheritance of resistance to wilt of Curtobacterium is complex, with more than three genes involved and a narrow-sense heritability of $29 \%$ for 'IAC Carioca Aruã' x 'SCS Guará' cross and 44\% for 'IAC Carioca Pyatã' x 'Pérola' cross.
\end{abstract}

Index terms: Curtobacterium flaccumfaciens pv. flaccumfaciens, Phaseolus vulgaris, genetic control, heritability, genetic resistance.

\section{Introdução}

A murcha bacteriana, causada por Curtobacterium flaccumfaciens pv. Alaccumfaciens foi identificada recentemente em várias regiões produtoras de feijão no Brasil (Valentini et al., 2010) e tem sido apontada como uma das doenças emergentes de maior importância para a cultura do feijão. O controle da doença está pautado na combinação de práticas culturais, inclusive o uso de sementes sadias, rotação de culturas e principalmente o uso de cultivares resistentes, que é o meio mais eficiente e econômico para o controle da murcha de Curtobacterium (Maringoni \& Camara, 2006; Herbes et al., 2008). Para o desenvolvimento de cultivares resistentes, o conhecimento da variabilidade do patógeno, fontes de resistência e o mecanismo de herança da resistência do hospedeiro são requisitos básicos.

Há poucos estudos sobre a herança da resistência à murcha de Curtobacterium em feijão. Os primeiros

Pesq. agropec. bras., Brasília, v.46, n.9, p.1045-1052, set. 2011 
foram realizados por Coyne et al. (1965, 1966). Esses autores demonstraram que a reação de resistência é determinada por dois genes recessivos, em dois cruzamentos com a linhagem PI 165078 como doador de alelos resistentes. No Brasil, Krause (2008) estudou o controle genético de características agronômicas e a reação à murcha de Curtobacterium, em feijão-vagem, por meio de dialelo. Os genitores 'Novirex', 'Manteiga Baixo' e 'IAC Carioca Tybatã' obtiveram a melhor capacidade geral de combinação, o que indica a presença de genes com efeito aditivo na redução da doença. As combinações 'Manteiga Baixo' x 'Novirex' e 'Manteiga Baixo' x 'Cota' destacaram-se por apresentar as menores estimativas negativas da capacidade específica de combinação.

Dada a importância dessa cultura no mundo, vêm sendo realizados vários trabalhos que buscam identificar acessos e cultivares portadores de alelos resistentes à doença e entender o comportamento do patógeno e da interação planta x patógeno (Hsieh et al., 2005; Souza et al., 2006; Huang et al., 2007). Nesse sentido, são imprescindíveis as pesquisas que utilizem os recursos genéticos disponíveis, para o melhor conhecimento da natureza e da magnitude dos efeitos gênicos que controlam a resistência, e escolha do método mais adequado a ser aplicado na seleção e na predição do comportamento de gerações segregantes e o desenvolvimento de novas cultivares de feijão.

O objetivo deste trabalho foi determinar a herança da resistência à murcha de Curtobacterium em feijão.

\section{Material e Métodos}

Os experimentos foram realizados em 2010, na Universidade do Estado de Santa Catarina, em Lages, $\mathrm{SC}$, a $27^{\circ} 47^{\prime} \mathrm{S}, 50^{\circ} 18^{\prime} \mathrm{W}$ e $916 \mathrm{~m}$ de altitude.

Cinco genótipos de feijão, com diferentes reações de resistência à murcha de Curtobacterium, foram cruzados em arranjo dialélico, pelo qual se obtiveram dezcombinaçõeshíbridas $F_{1}$ e dezhíbridos $F_{1}$ recíprocos. Os genótipos 'IAC Carioca Aruã', 'IAC Carioca Pyatã' e 'IAC Carioca Tybatã' foram utilizados como pais portadores de alelos que condicionam resistência à murcha de Curtobacterium, e 'Pérola' e 'SCS Guará' são genótipos suscetíveis à doença. Dois cruzamentos entre genótipos resistentes e suscetíveis - 'IAC Carioca Aruã' x 'SCS Guará' e 'IAC Carioca Pyatã' x 'Pérola' - foram realizados para dar origem às gerações fixas $\mathrm{P}_{1}, \mathrm{P}_{2}$ e $\mathrm{F}_{1}$ e às gerações segregantes $\mathrm{F}_{2}, \mathrm{RC}_{1}$ e $\mathrm{RC}_{2}$.

No primeiro experimento, o dialelo completo com os pais, os híbridos $F_{1}$ e os híbridos $F_{1}$ recíprocos foi avaliado em casa de vegetação, quanto à reação à murcha de Curtobacterium, em delineamento inteiramente casualizado, com dez repetições por tratamento, em que cada planta foi considerada uma repetição.

As duas famílias, compostas por seis gerações $-\mathrm{P}_{1}$, $\mathrm{P}_{2}, \mathrm{~F}_{1}, \mathrm{~F}_{2}, \mathrm{RC}_{1}$ e $\mathrm{RC}_{2}$ - foram avaliadas em um segundo experimento, novamente em casa de vegetação, com temperatura entre $20 \mathrm{e} 25^{\circ} \mathrm{C}$. Utilizou-se o delineamento inteiramente casualizado, com número diferente de plantas por geração, em que as gerações fixas $\mathrm{P}_{1}, \mathrm{P}_{2}$ e $\mathrm{F}_{1}$ foram compostas em média por 40 plantas, as gerações $\mathrm{F}_{2}$ foram compostas por 200 plantas, e as gerações de retrocruzamentos tiveram número variável, de acordo com a disponibilidade de sementes. Utilizou-se uma mistura de solo de barranco, esterco bovino curtido e substrato, corrigida conforme o recomendado para a cultura do feijão (Sociedade Brasileira de Ciência do Solo, 2004).

Para os dois experimentos, aos nove dias após a emergência das plantas, foi realizada a inoculação conforme Maringoni (2002). Utilizou-se o isolado Cff 2634 de C. flaccumfaciens pv. flaccumfaciens, cultivado em meio de cultura nutriente-sacarose-ágar, por 48 horas a $28^{\circ} \mathrm{C}$, em câmara de crescimento bacteriano. Após o crescimento das bactérias, foi feita a diluição em solução salina com $\mathrm{NaCl}$ a $0,85 \%$ até atingir a concentração de $10^{8} \mathrm{UFC} \mathrm{mL}^{-1}$, medida em espectrofotômetro Biophotometer (Eppendorf AG, Hamburgo, Alemanha) com densidade óptica de $600 \mathrm{~nm}$. A inoculação foi realizada através de duas punções no caule, entre as folhas cotiledonares e as folhas primárias, por meio de uma haste reta previamente umedecida na solução bacteriana.

A avaliação da severidade da doença foi realizada aos 30 dias após a inoculação da solução bacteriana nas plantas, tendo-se empregado uma escala de notas adaptada por Maringoni (2002), que indica: 0, plantas sem sintomas de doença; 1, sintoma de mosaico nas folhas; 2, poucas folhas murchas (de uma a três folhas, menos de 10\% das folhas das plantas); 5, 25\% de folhas com murcha e amarelecimento; $7,50 \%$ de folhas murchas, amarelecimento e necrose de folíolos, plantas com nanismo; 9, 75\% ou mais de folhas com 
murcha e necrose, queda prematura de folhas, nanismo severo e morte da planta.

Para a análise dialélica, utilizou-se o método I de Griffing (1956), admitindo o modelo como fixo (modelo I), para estimar a capacidade geral de combinação, a capacidade específica de combinação, o efeito recíproco, o efeito dos genes nucleares da mãe e o efeito extracromossômico. As médias dos parentais, híbridos $\mathrm{F}_{1}$ e híbridos $\mathrm{F}_{1}$ recíprocos foram comparadas pelo teste de Scott \& Knott, a 5\% de probabilidade.

As análises de variância, utilizadas para estimar as médias e variâncias das populações, foram realizadas para cada geração de cada família. As análises de médias de geração, pelo método dos quadrados mínimos ponderados, foram efetuadas para estimar os efeitos envolvidos na determinação da resistência genética à murcha de Curtobacterium, tendo-se utilizando os seis parâmetros do modelo completo, conforme Mather \& Jinks (1984) e Cruz \& Regazzi (1997). Com base nas estimativas do componente de média (m), aditivo (a) e de dominância (d), foram estimados outros parâmetros que referem-se às interações epistáticas (aa, ad e dd). A significância da hipótese de que cada parâmetro é nulo, isto é Ho: bi $=0$, foi avaliada pelo teste t. As médias das seis gerações de cada cruzamento foram comparadas pelo teste Student-Newman-Keuls (SNK), a $5 \%$ de probabilidade.

A partir das variâncias fenotípicas de cada geração foram estimados os componentes da variância genética e de ambiente para o caráter avaliado. No modelo completo de Mather \& Jinks (1984), tendo-se a geração $F_{2}$ como população de referência, foram estimados os componentes da variância ambiental na $\mathrm{F}_{2}$, variância genética, variância genética aditiva e variância genética dominante. A partir das estimativas dos componentes da variância, estimou-se a herdabilidade no sentido amplo e no sentido restrito. A estimativa do número de genes foi realizada pela fórmula descrita por Cruz \& Regazzi (1997), tendo-se considerado o grau médio de dominância com base nas variâncias (gmd). As análises foram realizadas pelo SAS (SAS Institute, 2007), Macro Diallel-SAS05 (Zhang et al., 2005), Genes (Cruz, 2006) e Sisvar (Ferreira, 2008).

\section{Resultados e Discussão}

Os genótipos 'IAC Carioca Aruã', 'IAC Carioca Pyatã' e 'IAC Carioca Tybatã' apresentaram as menores médias de severidade da murcha bacteriana, como já era esperado (1,6 a 1,9), enquanto 'Pérola' e 'SCS Guará' tiveram notas de severidade elevadas $(6,8$ a 8,2$)$, o que mostra suscetibilidade à doença (Tabela 1$)$. Os híbridos $\mathrm{F}_{1}$ e $\mathrm{F}_{1}$ recíprocos, do cruzamento 'IAC Carioca Aruã' $\mathrm{x}$ 'IAC Carioca Tybatã' (resistente $\mathrm{x}$ resistente) destacaram-se por apresentar médias superiores às dos pais $(6,70$ e 5,40$)$, o que indica que a resistência à murcha de Curtobacterium, nesses cruzamentos, é atribuída a genes com efeito recessivo, pois os alelos de resistência à doença dos pais não estão se manifestando nos filhos. Os cruzamentos entre os genótipos resistentes e suscetíveis 'IAC Carioca Aruã' x 'Pérola' e 'IAC Carioca Aruã' x 'Guará' ( $\mathrm{F}_{1}$ e recíprocos) apresentaram notas de severidade elevadas, e diferiram do pai resistente 'IAC Carioca Aruã', o que também indica que os genes de resistência são recessivos. Porém, os cruzamentos $\mathrm{F}_{1}$ e recíprocos do 'IAC Carioca Pyatã' x 'Pérola' e 'IAC Carioca Pyatã' x 'Guará', todos resistentes $\mathrm{x}$ suscetíveis, apresentaram médias inferiores à média dos pais, tendo diferido do pai suscetível, o que mostra que, para esses cruzamentos, a resistência foi dominante.

De acordo com a análise de variância dialélica, os pais diferiram em relação à capacidade geral de combinação (CGC), e os híbridos apresentaram distintas capacidades específicas de combinação (CEC) (Tabela 2). O fato de que tanto a CGC quanto a CEC foram significativas indica que ambos os efeitos aditivos e não aditivos estão envolvidos na resistência genética à murcha de Curtobacterium, nos genótipos estudados, e a magnitude do quadrado médio para a CGC indica a predominância de efeitos aditivos. Resultados semelhantes foram obtidos por Krause (2008), em dialelo com cinco genótipos de feijão-vagem, quanto à resistência à murcha de Curtobacterium.

$\mathrm{Na}$ cultura do feijão, buscam-se genitores com as mais altas estimativas de CGC cujos efeitos aditivos garantam maior concentração de alelos favoráveis e, assim, aumentem a probabilidade de se obter progresso genético no programa de melhoramento. Quando as estimativas da CGC são elevadas, independentemente de serem positivas ou negativas, o genitor em questão é muito superior ou muito inferior aos demais genitores do dialelo (Cruz \& Regazzi, 1997). Nesse sentido, o 
genitor 'IAC Carioca Pyatã' (Tabela 3) apresenta-se como uma importante fonte de genes, para diminuir a severidade da murcha de Curtobacterium e sua inclusão é recomendada em blocos de cruzamentos.

Duas combinações híbridas mostraram efeitos negativos e significativos da CEC (Tabela 3), o que indica a importância da ação gênica não aditiva nesses cruzamentos; entre essas combinações estão 'IAC Carioca Pyatã' x 'Pérola' e 'IAC Carioca Pyatã' x 'SCS Guará', as quais são recomendadas para recuperar genótipos promissores nas gerações avançadas, uma vez que envolvem um pai com elevada CGC. Em um programa de melhoramento de plantas autógamas, a CEC possui limitações para uso, pois o produto desejável no feijão são linhas puras (Nkalubo et al., 2009), a razão para isto está no fato de que a ação gênica dominante diminui quando as gerações são avançadas, pela redução na fração de plantas heterozigotas na população. Entretanto, o uso de cruzamentos cujas CEC são elevadas aumenta a probabilidade de se obter sucesso no processo de melhoramento de plantas autógamas. A significância dos cruzamentos recíprocos 'Pérola' x 'IAC Carioca Tybatã' e 'Guará' x 'IAC Carioca Tybatã' indica que ocorrem diferenças, quando esses genitores são utilizados como receptores ou doadores de pólen.

$\mathrm{O}$ efeito significativo dos genes nucleares da mãe, também conhecido como efeito materno, indica que genes nucleares maternos podem estar envolvidos no controle genético da característica herança da resistência à murcha de Curtobacterium, visto que os descendentes dos cruzamentos 'Pérola' x 'IAC Carioca Tybatã' e 'Guará' x 'IAC Carioca Tybatã' têm o mesmo fenótipo do genitor feminino. Os efeitos dos genes nucleares da mãe são responsáveis por certas condições no citoplasma do óvulo, provavelmente produtos gênicos. Contudo, é importante salientar que o efeito dos genes nucleares da mãe sobre o fenótipo do filho se dá apenas por uma ou, no máximo, duas gerações (Ramalho et al., 2008). Esses dados são de grande importância para os programas de melhoramento de feijão, uma vez que não havia informações sobre o comportamento dos híbridos recíprocos para a característica resistência à murcha de Curtobacterium.

Os pais utilizados no estudo das seis gerações não representam os genótipos extremos quanto à resistência e suscetibilidade à murcha de Curtobacterium, no entanto, não houve sobreposição das notas de severidade (Tabela 4). Os pais resistentes 'IAC Carioca Aruã' e 'IAC Carioca Pyatã' apresentaram médias de 0,89 e 0,51 , respectivamente, e diferiram significativamente dos pais suscetíveis, que tiveram notas de 4,31 ('SCS Guará') e 6,89 ('Pérola'). A maior variância nas gerações dos retrocruzamentos e $\mathrm{F}_{2}$, comparada às demais gerações, pode ser atribuída à maior segregação dos genes e, consequentemente, à maior amplitude na distribuição dos valores de severidade. A variação observada nos genitores suscetíveis à doença ('Pérola' e 'SCS Guará'), provavelmente, está relacionada ao complexo controle genético e ao efeito pronunciado do ambiente. Em estudos da resistência à antracnose, Nkalubo et al. (2009) identificaram genitores com alelos de resistência que apresentavam as mais baixas variâncias, em contrapartida, os genitores com variâncias elevadas eram os mais suscetíveis à doença.

$\mathrm{O}$ comportamento verificado nas gerações $\mathrm{F}_{1}$ e $\mathrm{F}_{2}$, para ambos os cruzamentos, indica que interações alélicas não aditivas estão envolvidas, uma vez que as médias são diferentes das médias dos pais. O cruzamento 'IAC Carioca Aruã' x 'SCS Guará' apresentou interação alélica de dominância, uma vez que as médias das populações $F_{1}$ e $F_{2}$ são significativamente iguais à média do genitor 'SCS Guará', o que indica que a resistência é dada por genes recessivos. O cruzamento 'IAC Carioca Pyatã' x 'Pérola' apresentou comportamento oposto, o que indica que os genes de resistência são dominantes, uma vez que a população

Tabela 1. Médias das notas de severidade da murcha de Curtobacterium, para genitores, híbridos $\mathrm{F}_{1}$ e híbridos $\mathrm{F}_{1}$ recíprocos, pela escala de notas proposta por Maringoni (2002), no dialelo completo com cinco genótipos de feijoeiro ${ }^{(1)}$.

\begin{tabular}{lccccc}
\hline Genótipo & 'IAC Carioca Aruã' & 'IAC Carioca Pyatã' & 'IAC Carioca Tybatã' & 'Pérola' & 'SCS Guará' \\
\hline 'IAC Carioca Aruã' & $1,7 \mathrm{a}$ & $2,1 \mathrm{a}$ & $6,7 \mathrm{~b}$ & $7,4 \mathrm{c}$ & $6,3 \mathrm{~b}$ \\
'IAC Carioca Pyatã' & $2,4 \mathrm{a}$ & $1,9 \mathrm{a}$ & $1,3 \mathrm{a}$ & $0,9 \mathrm{a}$ & $1,5 \mathrm{a}$ \\
'IAC Carioca Tybatã' & $5,4 \mathrm{~b}$ & $1,5 \mathrm{a}$ & $1,6 \mathrm{a}$ & $3,9 \mathrm{a}$ & \\
'Pérola' & $7,4 \mathrm{c}$ & $1,6 \mathrm{a}$ & $6,4 \mathrm{~b}$ & $6,8 \mathrm{~b}$ & $8,6 \mathrm{a}$ \\
'SCS Guará' & $7,4 \mathrm{c}$ & $2,4 \mathrm{a}$ & $4,9 \mathrm{~b}$ & $7,6 \mathrm{c}$ & $8,2 \mathrm{c}$ \\
\hline
\end{tabular}

${ }^{(1)}$ Médias seguidas de letras iguais, não diferem, pelo teste Scott \& Knott, a 5\% de probabilidade. 
$\mathrm{F}_{1}$ é significativamente igual à população parental resistente ('IAC Carioca Pyatã').

O efeito gênico, envolvido com a resistência genética à murcha de Curtobacterium, foi investigado por meio de análise das médias das gerações das duas famílias por meio do modelo completo (Tabela 5). Pelo menos um dos tipos de epistasia (aa, ad ou dd) foi significativo para os dois conjuntos de gerações estudadas, o que indica a importância de se utilizar o modelo completo nas análises (Nkalubo et al., 2009). A significância dos efeitos aditivos (a) e aditivos-aditivos (aa), para o cruzamento 'IAC Carioca Aruã' x 'SCS Guará', indica que há possibilidade de a característica ser fixada com a seleção nas gerações seguintes. As técnicas de melhoramento de plantas autógamas se beneficiam da alta variância aditiva e da interação aditiva x aditiva, pois é possível obter ganhos genéticos satisfatórios (Gravina et al., 2004).

Por definição, o componente de efeito aditivo (a) nunca seria negativo, enquanto o sinal do componente dos desvios de dominância (d) depende da direção predominante da dominância (Mather \& Jinks, 1984). A existência do componente aditivo, com sinal negativo, é explicada pelo fato de que nem sempre o genitor $\mathrm{P}_{1}$, assim como seu respectivo retrocruzamento $\left(\mathrm{RC}_{1}\right)$, se

Tabela 2. Análise de variância das notas de severidade da murcha de Curtobacterium, de acordo com o método de Griffing (1956), no dialelo completo com cinco genótipos de feijoeiro.

\begin{tabular}{lccc}
\hline Fonte de variação & GL & Quadrado médio & F \\
\hline Tratamento & 24 & 74,371 & $15,180^{* *}$ \\
Capacidade geral de combinação & 4 & 286,203 & $58,409^{* *}$ \\
Capacidade específica de combinação & 10 & 51,924 & $10,597^{* *}$ \\
Efeito recíproco & 10 & 11,340 & $2,314^{*}$ \\
Efeito de genes nucleares da mãe & 4 & 21,500 & $4,387^{* *}$ \\
Efeito extracromossômico & 6 & 4,567 & $0,932^{\text {ns }}$ \\
Erro & 215 & 4,899 & \\
\hline
\end{tabular}

${ }^{n}$ Não significativo. * e **Significativo a 5 e $1 \%$ de probabilidade, pelo teste $\mathrm{F}$. refere ao genótipo com maior expressão do caráter que, nesse caso, seria o genótipo de maior suscetibilidade à doença. Neste caso, o genitor $\mathrm{P}_{1}$ com maior resistência é aquele que recebeu as menores notas de severidade e, consequentemente, menor média, por isso o sinal negativo do efeito aditivo foi verificado.

No cruzamento 'IAC Carioca Pyatã' x 'Pérola', o efeito aditivo (a) foi negativo, porém apresentou menor amplitude em comparação aos efeitos não aditivos. A ação gênica não aditiva é atribuída somente aos efeitos de dominância (d), mas também aos efeitos aditivo-dominante (ad) e dominante-dominante (dd), o que indica que os genes que controlam a resistência à murcha de Curtobacterium não agem independentemente (Cruz et al., 2006). Os efeitos epistáticos são mais importantes para o melhorista de espécies autógamas do que os efeitos de dominância, pelo fato de que a dominância é quebrada com as gerações de autofecundação. A epistasia, no entanto, não depende dos locos em heterozigose e pode permitir um maior número de combinações de genes do que a dominância (Omo-ikerodah et al., 2008).

$\mathrm{O}$ sinal associado à previsão do efeito de dominância indica o genitor que concentra o maior número de genes para diminuir ou incrementar a característica e, por convenção, os resultados de sinal negativo são utilizados para $\mathrm{P}_{1}$ e de sinal positivo para $\mathrm{P}_{2}$. Então, o sinal negativo indica que o genótipo 'IAC Carioca Pyatã' $\left(\mathrm{P}_{1}\right)$ concentra o maior número de genes para diminuir a severidade da murcha de Curtobacterium. O cruzamento 'IAC Carioca Pyatã' x 'Pérola' mostrou ser promissor para diminuir a severidade da murcha de Curtobacterium, no entanto, a presença de efeitos de dominância prejudica a seleção quanto à resistência em gerações segregantes, visto que estes efeitos tendem a desaparecer, o que indica a conveniência de seleção mais rigorosa, a partir de uma fase mais tardia de endogamia.

Tabela 3. Capacidade geral de combinação (CGC), capacidade específica de combinação (acima da diagonal) e efeito recíproco (abaixo da diagonal), das notas de severidade da murcha de Curtobacterium, de acordo com o método de Griffing (1956), no dialelo completo com cinco genótipos de feijão.

\begin{tabular}{lcccccc}
\hline Genótipo & 'IAC Carioca Aruã' & 'IAC Carioca Pyatã'" 'IAC Carioca Tybatã' & 'Pérola' & 'SCS Guará' & CGC \\
\hline 'IAC Carioca Aruã' & - & 0,041 & $2,019^{*}$ & $1,109^{*}$ & $4,346^{*}$ & $0,541^{*}$ \\
'IAC Carioca Pyatã', & 0,150 & - & 0,467 & $1,947^{*}$ & $3,880^{*}$ & $2,553^{*}$ \\
'IAC Carioca Tybatã' & 0,650 & 0,100 & - & 0,213 & 0,540 & $0,813^{*}$ \\
'Pérola' & 0,000 & 0,350 & $1,250^{*}$ & - & 1,420 & $1,447^{*}$ \\
'SCS Guará' & 0,550 & 0,450 & $1,650^{*}$ & 0,550 & - & $1,377^{*}$ \\
\hline
\end{tabular}

*Significativo a $5 \%$ de probabilidade, pelo teste $\mathrm{t}$. 
Apesar de o efeito de dominância ser superior ao da aditividade (a), pela decomposição não ortogonal (Tabela 5), é possível verificar que os efeitos aditivos apresentam maior importância na determinação do caráter nos dois cruzamentos. Esses resultados

Tabela 4. Número de plantas avaliadas $(\mathrm{n})$, média $(\mu)$, variância $\left(\sigma^{2}\right)$ e erro padrão da média $\left(\sigma_{\mu}\right)$, das notas de severidade da murcha de Curtobacterium, para as seis gerações $\left(\mathrm{P}_{1}, \mathrm{P}_{2}, \mathrm{~F}_{1}, \mathrm{~F}_{2}, \mathrm{RC}_{1}\right.$ e $\left.\mathrm{RC}_{2}\right)$ dos cruzamentos de feijão 'IAC Carioca Aruã' x 'SCS Guará' e 'IAC Carioca Pyatã'" x 'Pérola' ${ }^{\prime(1)}$.

\begin{tabular}{lcccc}
\hline Geração & $\mathrm{n}$ & $\mu$ & $\sigma^{2}$ & $\sigma_{\mu}$ \\
\hline \multicolumn{5}{c}{ 'IAC Carioca Aruã' x 'SCS Guará' } \\
$\mathrm{P}_{1}$ & 38 & $0,895 \mathrm{a}$ & 0,529 & 0,014 \\
$\mathrm{P}_{2}$ & 38 & $4,316 \mathrm{c}$ & 6,005 & 0,158 \\
$\mathrm{~F}_{1}$ & 44 & $4,522 \mathrm{c}$ & 6,022 & 0,137 \\
$\mathrm{~F}_{2}$ & 206 & $4,388 \mathrm{c}$ & 7,994 & 0,039 \\
$\mathrm{RC}_{1}$ & 15 & $2,533 \mathrm{~b}$ & 6,695 & 0,446 \\
$\mathrm{RC}_{2}$ & 27 & $4,740 \mathrm{c}$ & 6,968 & 0,258 \\
\hline \multicolumn{5}{c}{ 'IAC Carioca Pyatã' x 'Pérola' } \\
$\mathrm{P}_{1}$ & 45 & $0,511 \mathrm{a}$ & 0,891 & 0,020 \\
$\mathrm{P}_{2}$ & 39 & $6,897 \mathrm{c}$ & 5,884 & 0,151 \\
$\mathrm{~F}_{1}$ & 44 & $0,773 \mathrm{a}$ & 0,738 & 0,016 \\
$\mathrm{~F}_{2}$ & 208 & $2,043 \mathrm{~b}$ & 7,404 & 0,035 \\
$\mathrm{RC}_{1}$ & 32 & $0,594 \mathrm{a}$ & 0,765 & 0,024 \\
$\mathrm{RC}_{2}$ & 37 & $2,648 \mathrm{~b}$ & 10,734 & 0,290 \\
\hline
\end{tabular}

${ }^{(1)}$ Médias seguidas de letras iguais não diferem, pelo teste SNK, a 5\% de probabilidade. evidenciam a possibilidade de obtenção de genótipos homozigotos superiores, a partir da seleção nas populações provenientes da geração $F_{2}$ (Schuelter et al., 2003).

As análises das variâncias das seis gerações concordam com os resultados encontrados pela análise das médias, em que o efeito aditivo contribuiu mais para explicar a herança de resistência à murcha de Curtobacterium (Tabela 6). A herdabilidade no sentido restrito aponta que 29 e 44\%, respectivamente, para os cruzamentos 'IAC Carioca Aruã' x 'SCS Guará' e 'IAC Carioca Pyatã' x 'Pérola', é atribuída a causas genéticas de natureza aditiva e, portanto, há possibilidade de se obterem ganhos com a seleção, o que pode ser evidenciado, também, pela superioridade dos efeitos aditivos aos efeitos de dominância. A herdabilidade da população para 'IAC Carioca Aruã' x 'SCS Guará' foi relativamente inferior à da população 'IAC Carioca Pyatã' x 'Pérola', pelo fato de o ambiente ter exercido considerável influência na expressão deste caráter para a primeira população e, portanto, ter causado a diminuição da porção do fenótipo que pode ser herdado. É importante ressaltar que, apesar de as herdabilidades obtidas no presente trabalho serem uma propriedade do caráter válida apenas para a população, e das condições ambientais a que os indivíduos foram

Tabela 5. Estimativa da média geral (m) e dos desvios, em razão dos efeitos aditivos (a), dos efeitos de dominância (d), efeitos epistáticos do tipo aditivo aditivo (aa), aditivo dominante (ad) e dominante dominante (dd) e da decomposição não ortogonal da soma de quadrados dos seis parâmetros, pelo método de eliminação de Gauss, obtidos para as notas de severidade da murcha de Curtobacterium, para as seis gerações $\left(\mathrm{P}_{1}, \mathrm{P}_{2}, \mathrm{~F}_{1}, \mathrm{~F}_{2}, \mathrm{RC}_{1}\right.$ e $\left.\mathrm{RC}_{2}\right)$ dos cruzamentos de feijoeiro 'IAC Carioca Aruã' x 'SCS Guará' e 'IAC Carioca Pyatã' x 'Pérola'.

\begin{tabular}{|c|c|c|c|c|c|c|c|c|}
\hline Parâmetro & GL & Estimativa & Variância & $\mathrm{t}$ & Fonte de variação & GL & SQ & $\mathrm{R} 2(\%)$ \\
\hline & \multicolumn{8}{|c|}{ 'IAC Carioca Aruã' x 'SCS Guará' } \\
\hline $\mathrm{m}$ & 319 & 5,61 & 3,482 & $3,007 *$ & $\mathrm{~m} / \mathrm{a}, \mathrm{d}, \mathrm{aa}, \mathrm{ad}, \mathrm{dd}$ & 1 & 1,285 & 16,366 \\
\hline $\mathrm{a}$ & 74 & 1,71 & 0,043 & $8,249 *$ & $\mathrm{a} / \mathrm{m}, \mathrm{d}, \mathrm{aa}, \mathrm{ad}, \mathrm{dd}$ & 1 & 5,852 & 74,544 \\
\hline d & 362 & 3,801 & 28,368 & 0,713 & $\mathrm{~d} / \mathrm{m}, \mathrm{a}, \mathrm{aa}, \mathrm{ad}, \mathrm{dd}$ & 1 & 0,102 & 1,300 \\
\hline aa & 245 & 3,005 & 3,438 & $1,620^{*}$ & $\mathrm{aa} / \mathrm{m}, \mathrm{a}, \mathrm{d}, \mathrm{ad}, \mathrm{dd}$ & 1 & 0,376 & 4,793 \\
\hline ad & 114 & 0,994 & 2,989 & 0,574 & $\mathrm{ad} / \mathrm{m}, \mathrm{a}, \mathrm{d}, \mathrm{aa}, \mathrm{dd}$ & 1 & 0,098 & 1,258 \\
\hline dd & 362 & 2,713 & 12,611 & 0,764 & $\mathrm{dd} / \mathrm{m}, \mathrm{a}, \mathrm{d}, \mathrm{aa}, \mathrm{ad}$ & 1 & 0,136 & 1,736 \\
\hline \multirow[t]{2}{*}{ Total } & - & - & - & - & - & 6 & 7,85 & 99,999 \\
\hline & \multicolumn{8}{|c|}{ 'IAC Carioca Pyatã' x 'Pérola' } \\
\hline $\mathrm{m}$ & 356 & 5,392 & 1,868 & $3,945 *$ & $\mathrm{~m} / \mathrm{a}, \mathrm{d}, \mathrm{aa}, \mathrm{ad}, \mathrm{dd}$ & 1 & 1,187 & 5,142 \\
\hline $\mathrm{a}$ & 82 & 3,193 & 0,042 & $15,458 *$ & $\mathrm{a} / \mathrm{m}, \mathrm{d}, \mathrm{aa}, \mathrm{ad}, \mathrm{dd}$ & 1 & 20,392 & 88,352 \\
\hline d & 399 & 8,777 & 13,984 & $2,347 *$ & $\mathrm{~d} / \mathrm{m}, \mathrm{a}, \mathrm{aa}, \mathrm{ad}, \mathrm{dd}$ & 1 & 0,544 & 2,359 \\
\hline aa & 274 & 1,688 & 1,825 & 1,249 & $\mathrm{aa} / \mathrm{m}, \mathrm{a}, \mathrm{d}, \mathrm{ad}, \mathrm{dd}$ & 1 & 0,118 & 0,514 \\
\hline $\mathrm{ad}$ & 149 & 2,276 & 1,427 & $1,906^{*}$ & $\mathrm{ad} / \mathrm{m}, \mathrm{a}, \mathrm{d}, \mathrm{aa}, \mathrm{dd}$ & 1 & 0,518 & 2,245 \\
\hline dd & 399 & 4,157 & 5,832 & $1,721 *$ & $\mathrm{dd} / \mathrm{m}, \mathrm{a}, \mathrm{d}, \mathrm{aa}, \mathrm{ad}$ & 1 & 0,32 & 1,387 \\
\hline Total & - & - & - & - & - & 6 & 23,081 & 99,999 \\
\hline
\end{tabular}

*Significativo a $5 \%$ de probabilidade, pelo teste $\mathrm{t}$. 
Tabela 6. Estimativa dos componentes de variância fenotípica, genotípica, aditiva, de dominância e ambiental, herdabilidade do sentido amplo, herdabilidade no sentido restrito, grau médio de dominância e número de genes, para as notas de severidade da murcha de Curtobacterium, para as seis gerações $\left(\mathrm{P}_{1}, \mathrm{P}_{2}, \mathrm{~F}_{1}, \mathrm{~F}_{2}, \mathrm{RC}_{1}\right.$ e $\left.\mathrm{RC}_{2}\right)$ dos cruzamentos de feijoeiro 'IAC Carioca Aruã' x 'SCS Guará' e 'IAC Carioca Pyatã' x 'Pérola'.

\begin{tabular}{lcc}
\hline Parâmetro & $\begin{array}{c}\text { 'IAC Carioca Aruã' } \\
\text { x 'SCS Guará' }\end{array}$ & $\begin{array}{c}\text { 'IAC Carioca Pyatã' } \\
\text { x 'Pérola' }\end{array}$ \\
\hline Variância fenotípica & 7,994 & 7,404 \\
Variância genotípica & 3,349 & 5,341 \\
Variância aditiva & 2,325 & 3,308 \\
Variância de dominância & 1,024 & 2,032 \\
Variância ambiental na F2 & 4,645 & 2,062 \\
Herdabilidade no sentido amplo & 41,898 & 72,138 \\
Herdabilidade no sentido restrito & 29,090 & 44,685 \\
Grau médio de dominância & 0,938 & 1,108 \\
Número de genes & 4,353 & 3,060 \\
\hline
\end{tabular}

submetidos, elas são um forte indicativo da magnitude da herdabilidade quanto à resistência à murcha de Curtobacterium (Cruz \& Regazzi, 1997). As baixas herdabilidades são um indicativo de que a herança de resistência à murcha de Curtobacterium é complexa $\mathrm{e}$ a obtenção de cultivares resistentes é difícil e demanda muito trabalho para os programas de melhoramento.

A estimativa do número de genes confirma o caráter quantitativo da herança da resistência, encontrado anteriormente por Coyne et al. (1965, 1966). Esses valores não podem ser tomados de forma absoluta, mas sim como um indicativo do tipo de herança envolvida, se é de natureza mono-, oligo- ou poligênica. Além disso, pode-se verificar que cada cruzamento tem particularidades, conforme os genótipos utilizados e os fatores externos que interferem, já que a estimativa do número de genes é muito sensível à variação ambiental.

\section{Conclusões}

1. O genitor 'IAC Carioca Pyatã' apresenta a melhor capacidade geral de combinação e é adequado o seu uso em blocos de cruzamentos, para o desenvolvimento de cultivares de feijão resistentes à murcha de Curtobacterium.

2. Os efeitos aditivos têm maior participação na variância genética total, quanto ao controle genético de resistência à murcha de Curtobacterium.
3. A herança da resistência à murcha de Curtobacterium é complexa, com mais de três genes envolvidos.

4. A herdabilidade no sentido restrito quanto à resistência à murcha de Curtobacterium é de $29 \%$ para o cruzamento 'IAC Carioca Aruã' x 'SCS Guará' e de $44 \%$ para o cruzamento 'IAC Carioca Pyatã' x 'Pérola'.

\section{Referências}

COYNE, D.P.; SCHUSTER, M.L.; ESTES, L.W. Effect of maturity and environment on the genetic control of reaction to wilt bacterium in Phaseolus vulgaris L. crosses. Journal of the American Society for Horticultural Science, v.88, p.393-399, 1966.

COYNE, D.P.; SCHUSTER, M.L.; YOUNG, J.O. A genetic study of bacterial wilt (Corynebacterium flaccumfaciens var. aurantiacum) tolerance in Phaseolus vulgaris crosses and the development of tolerance to two bacterial diseases in beans. Journal of the American Society for Horticultural Science, v.87, p.279-285, 1965.

CRUZ, C.D. Programa Genes: biometria. Viçosa: UFV, 2006. $382 \mathrm{p}$.

CRUZ, C.D.; REGAZZI, A.J. Modelos biométricos aplicados ao melhoramento genético. Viçosa: UFV, 1997. 390p.

CRUZ, R.P. da; MILACH, S.C.K.; FEDERIZZI, L.C. Inheritance of rice cold tolerance at the germination stage. Genetics and Molecular Biology, v.29, p.314-320, 2006.

FERREIRA, D.F. SISVAR: um programa para análises e ensino de estatística. Revista Symposium, v.6, p.36-41, 2008.

GRAVINA, G. de A.; MARTINS FILHO, S.; SEDIYAMA, C.S.; CRUZ, C.D. Parâmetros genéticos da resistência da soja a Cercospora sojina. Pesquisa Agropecuária Brasileira, v.39, p.653-659, 2004.

GRIFFING, B. Concept of general and specific combining ability in relation to diallel crossing systems. Australian Journal of Biological Sciences, v.9, p.463-493, 1956.

HERBES, D.H.; THEODORO, G.F.; MARINGONI, A.C.; PIVA, C.A. dal; ABREU, L. de. Detecção de Curtobacterium flaccumfaciens pv. flaccumfaciens em sementes de feijoeiro produzidas em Santa Catarina. Tropical Plant Pathology, v.33, p.53-156, 2008.

HSIEH, T.F.; HUANG, H.C.; MÜNDEL, H.H.; CONNER, R.L.; ERICKSON, R.S.; BALASUBRAMANIAN, P.M. Resistance of common bean (Phaseolus vulgaris) to bacterial wilt caused by Curtobacterium flaccumfaciens pv. flaccumfaciens. Phytopathology, v.153, p.245-249, 2005.

HUANG, H.-C.; MÜNDEL, H.-H.; ERICKSON, R.S.; CHELLE, C.D.; BALASUBRAMANIAN, P.M.; KIEHN, F.; CONNER, R.L. Resistance of common bean (Phaseolus vulgaris L.) cultivars and germplasm lines to the purple variant of bacterial wilt (Curtobacterium flaccumfaciens pv. flaccumfaciens). Plant Pathology Bulletin, v.16, p.91-95, 2007. 
KRAUSE, W. Fontes de resistência, métodos de inoculação e capacidade de combinação para a resistência à murcha-de-curtobacterium em feijão-de-vagem. 2008. 108p. Tese (Doutorado) - Universidade Norte Fluminense, Campos dos Goytacazes.

MARINGONI, A.C. Comportamento de cultivares de feijoeiro comum à murcha-de-curtobacterium. Fitopatologia Brasileira, v.27, p.157-162, 2002.

MARINGONI, A.C.; CAMARA, R.C. de. Curtobacterium flaccumfaciens pv. flaccumfaciens detection in bean seeds using a semi-selective culture medium. Brazilian Journal of Microbiology, v.37, p.451-455, 2006.

MATHER, K.; JINKS, J.L. Introdução à genética biométrica. Ribeirão Preto: Sociedade Brasileira de Genética, 1984. 242p.

NKALUBO, S.T.; MELIS, R.; DERERA, L.; MARK, D.L.; OPIO, F. Genetic analysis of anthracnose resistance in common bean breeding source germplasm. Euphytica, v.167, p.303-312, 2009.

OMO-IKERODAH, E.E.; FATOKUN, C.A.; FAWOLE, I. Genetic analysis of resistance to flower bud thrips (Megalurothrips sjostedti) in cowpea (Vigna unguiculata L. Walp.). Euphytica, v.165, p.145-154, 2008.

RAMALHO, M.A.P.; SANTOS, J.B. dos; PINTO, C.A.B.P. Genética na agropecuária. 4.ed. Lavras: UFLA, 2008. 461p.
SAS INSTITUTE. SAS for Windows Microsoft. Version 9.1.3. Cary: SAS Institute, 2007.

SCHUELTER, A.R.; SOUZA, I.R.P. de; TAVARES, F.F.; SANTOS, M.X. dos; OLIVEIRA, E. de; GUIMARÃES, C.T. Controle genético da resistência do milho à mancha por Phaeosphaeria. Revista Brasileira de Milho e Sorgo, v.2, p.80-86, 2003.

SOCIEDADE BRASILEIRA DE CIÊNCIA DO SOLO. Comissão de Química e Fertilidade do Solo. Manual de adubação e calagem para os estados do Rio Grande do Sul e Santa Catarina. 10.ed. Porto Alegre: SBCS, 2004. 400p.

SOUZA, V.L. de; MARINGONI, A.C.; CARBONELL, S.A.M.; ITO, M.F. Resistência genética em genótipos de feijoeiro a Curtobacterium flaccumfaciens pv. flaccumfaciens. Summa Phytopathologica, v.32, p.339-344, 2006.

VALENTINI, G.; GUIDOLIN, A.F.G.; BALDISSERA, J.N. da C.; COIMBRA, J.L.M. Curtobacterium flaccumfaciens pv. flaccumfaciens: etiologia, detecção e medidas de controle. Revista Biotemas, v.23, p.1-8, 2010.

ZHANG, Y.D.; KANG, M.S.; LAMKEY, K.R. Diallel-Sas05: a comprehensive program for Griffing's and Gardner-Eberhart analyses. Agronomy Journal, v.97, p.1097-1106, 2005.

$\overline{\text { Recebido em } 27 \text { de maio de } 2010 \text { e aprovado em } 8 \text { de agosto de } 2011}$ 